\title{
Observaciones acerca de la experiencia polisémica del arte*
}

\author{
Remarks on the Polysemic Experience of Art
}

\author{
Rodrigo Laera \\ Universidad de Barcelona (España)
}

Recibido: 2015-07-27

Envío a pares: 2015-08-14

Aprobado por pares: $2015-10-20$

Aceptado: 2015-10-28

Pensamiento y Cultura | ISSN: 0123-0999 | eISSN: 2027-5331

pensam.cult | Vol. 18-2 | Diciembre de 2015 | pp. 75-94

DOI: 10.5294/pecu.2015.18.2.4

\section{Para citar este artículo/To reference this article}

Laera, Rodrigo. 2015. "Observaciones acerca de la experiencia polisémica del arte", Pensamiento y Cultura 18 (2): 75-94. DOI: 10.5294/pecu.2015.18.2.4

* Adscrito al proyecto "El horizonte de lo común (entre una subjetividad no personal y una comunidad no identitaria)" de la Cátedra de Filosofía Contemporánea de la Universidad de Barcelona.

$\diamond$ rodrigolaera@gmail.com 


\section{Observaciones acerca de la experiencia polisémica del arte}

Resumen: el objetivo principal de este trabajo consiste en indagar acerca de la experiencia polisémica del arte de acuerdo con dos tesis principales. La primera sostiene que el arte brinda un conocimiento no trivial acerca de una parcela importante del mundo. La segunda mantiene que ese tipo de conocimiento puede ser no-conceptual. Ambas tesis se sostienen a partir de la idea de que el arte no solo posee una unidad de sentido acabada y absoluta, sino que además en él surgen racimos de significados que se recrean permanentemente -aun si se puede identificar un significado estándar.

Palabras clave: cognitivismo; epistemología del arte; experiencia polisémica; significado.

\section{Remarks on the Polysemic Experience of Art}

Abstract: The main purpose of this paper is to inquire about the polysemic experience of art based on two key theses. The first one states that art provides a non-trivial knowledge of an important area of the world. The second one states that this kind of knowledge might be non-conceptual. Both are based on the idea that art not only possesses a final and absolute unit of meaning, but that it also generates clusters of meaning that are permanently recreated, even if a standard meaning is identifiable.

Keywords: Cognitivism; epistemology of art; polysemic experience; meaning. 


\section{Introducción}

El cognitivismo estético sostiene la conjunción de dos afirmaciones: (a) que el arte puede brindarnos un tipo de conocimiento no trivial acerca del mundo; (b) que la capacidad del arte para brindarnos este conocimiento no trivial determina su valor. Por el contrario, el anti-cognitivismo estético se desarrolla a partir de la negación de una o ambas afirmaciones. Algunos partidarios del cognitivismo estético fueron, por ejemplo, Beardsmore (1971), Goodman (1976) o Nussbaum (1990). Algunos de los anti-cognitivistas fueron, por ejemplo, Stolnitz (1992) o Diffey (1997).

Generalmente, quienes adhieren al cognitivismo estético se sitúan del lado de la representación, mientras que el anti-cognitivismo rechaza la idea de que la representación sea uno de los constituyentes esenciales del arte (cfr. Levingston, 2005). Ahora bien, ¿es posible ser cognitivista pensando que el arte no es mera representación? Dicho de otra manera, si el arte excede el dominio de la representación, entonces ¿habría que pensarlo como algo que se encuentra más allá del mundo en que nos toca vivir? De ser así, ¿cómo es posible que nos brinde algún tipo de conocimiento no trivial? Este artículo está destinado a indagar en estas dos preguntas, exponiendo la dialéctica entre la realidad e irrealidad de la obra de arte a través de lo que se llamará experiencia polisémica del arte. La tesis general que se expondrá sostiene que el arte brinda un tipo de conocimiento de mundos posibles y que estos mundos suscitan sensaciones mediante dichas experiencias polisémicas. Así, el arte se desconecta de la cotidianidad mediante significantes no conceptuales, situándose de este modo en el reino de la posibilidad, más que en el reino de la representación.

\section{El carácter epistemológico de la experiencia polisémica del arte}

Peacocke $(1992,2001)$ ha distinguido entre las propiedades representacionales y las propiedades sensacionales de la percepción. Las primeras aluden a la experiencia que se tiene cuando uno se pregunta 
— generalmente de manera tácita-cómo puede describirse el mundo. Con lo cual estas propiedades implican una descripción de los hechos que ocurren, ocurrieron u ocurrirían. La complejidad de tales propiedades estriba en su valor semántico, pues la descripción realizada se encuentra entre otras alternativas que brinda la experiencia del objeto presentado. En cambio, las propiedades sensacionales son aquellas que la experiencia tiene en virtud de su carácter fenoménico. Si bien este tipo de propiedades no son figurativas, pueden vincularse causalmente con una determinada experiencia estética, y justamente por este motivo puede ser vista como más anárquica de lo que comúnmente estamos dispuestos a admitir. A modo de ejemplo, escuchar un intervalo como una quinta disminuida y no como una aumentada es una cuestión sensacional, que es distinta a las propiedades representativas de la música. De la misma manera que uno es capaz de escuchar esa quinta disminuida sin poseer su respectivo concepto, también la música pude llegar a representar algo sin que se posea el concepto de aquello que representa (véase también: Evans, 1985). ${ }^{1}$

Esta diferencia conduce a dos observaciones elementales respecto de la experiencia estética. La primera es que tal experiencia puede llegar a pensarse como una cualidad en sí misma, que no necesita especialmente una pre-comprensión del mundo para manifestarse, aunque comprender una parcela del mundo quizás ayude. Sin embargo, el problema que presenta esta perspectiva radica en sus matices, pues parece muy complicado probar hasta qué punto un sujeto es capaz de experimentar algo sin un ámbito semántico que lo condicione. La segunda observación, quizás más importante, consiste en que la diferencia entre propiedades representacionales y sensacionales aplicadas a la estética puede llevar a pensar la experiencia estética sin que medie ningún juicio de valor. En efecto, es posible pensar que una de las características intrínsecas de la obra de arte es que ningún juicio que se haga acerca de ella puede capturarla en su totalidad. La experiencia estética no se situaría en un plano semántico, con lo que se rechazaría

1 Para conocer una opinión contraria, llamada en epistemología conceptualismo, véase McDowell (1994/2007). 
cualquier tipo de explicación del arte, justamente por tratarse de una explicación. ${ }^{2}$ Por tanto, las propiedades representacionales del lenguaje referencial serían incomparables con las propiedades sensacionales de la experiencia estética. O mejor, las propiedades sensacionales de la experiencia estética serían irreductibles a las propiedades representacionales del lenguaje referencial. En consecuencia, si la experiencia estética no nos puede decir nada acerca de la experiencia propia del arte, entonces deberíamos perder todo interés en lo que constituye la naturaleza de la experiencia estética.

La anterior posición al menos intuitivamente parece acertada, alcanza con escuchar cualquier sinfonía, leer sus críticas y echar un vistazo a los adjetivos que se emplean cuando se la quiere describir, para darse cuenta de que nunca la representarán fielmente. Pero de seguir por este camino, el arte sería un absoluto que se reafirma en sus múltiples experiencias sin referirse a nada distinto de sí, y no se trataría de una identidad tautológica, sino de una solipsista. En efecto, la raíz de este problema es que el arte quedaría condenado al silencio, no podríamos conocer nada a partir de él. Y aunque la experiencia estética fuera una finalidad sin fin, no podría haber reconocimiento alguno de dicha experiencia como tal, porque no podemos comunicar lingüísticamente - ni siquiera a uno mismoaquello de lo que no tenemos un acceso semántico.

Como se ha dicho, los problemas de la relación entre la semántica y la experiencia estética se encuentra en los matices, pues no resulta acertado concluir lo siguiente: dado que la experiencia estética excluye el contenido conceptual, toda conceptualización del arte no respondería a una experiencia genuina del arte, pues el juicio siempre la estaría falseando al introducir el concepto. Si esto fuera cierto, entonces el análisis de la experiencia estética nunca podría ser encarado desde la perspectiva de la psicología experimental, pues dicha psicología intentaría responder la pregunta acerca de qué es una experiencia estética para un sujeto, cuyo acceso es siempre conceptual. Luego, habría una experiencia singular, incomunicable y, por consiguiente, inalcanzable no solo para cualquier tipo de psicología, sino también para cualquier fenomenología (en el

Partidario de este punto de vista es, por ejemplo, Wittgenstein (1992). 
sentido amplio de la palabra). Y de ser así, ¿cómo podríamos saber que lo que estamos viviendo es, en definitiva, una experiencia estética y no otro tipo de experiencia?

Asumiendo que la experiencia estética favorezca a la construcción de una parcela importante de la experiencia humana, esta construcción sería de algún modo indirecta. En primer lugar, la experiencia estética no se constituye como la dimensión propia de un sujeto aislado, oponiéndola a la realidad colectiva o social como si fuera "lo otro". En segundo lugar, que la experiencia estética tenga un carácter social no implica que no existan propiedades sensacionales que la causen. En todo caso, existirían causas cooperantes (el orden de lo social y el orden sensacional). Estas causas implican entablar juicios de valor, pretensiones de validez que legitimen a la obra de arte. La experiencia estética se encuentra ligada al contexto a la vez que trascienden el contexto.

Más allá de presuponer que la experiencia estética en general sea no-conceptual, varios cognitivistas también han sostenido que el arte nos puede brindar un conocimiento práctico, el conocimiento de cómo hacer ciertas cosas. Siguiendo con este enfoque, se ha sostenido que el arte puede enseñarnos cómo sentir apropiadamente o educar nuestras emociones (p. ej., Robinson, 2005), que puede mejorar el razonamiento práctico (Putnam, 1978), o también puede pensarse, como sostiene Currie (2004), que el arte puede mejorar las capacidades imaginativas necesarias para planificar y comprender a los demás. Sin embargo, esta posición se refiere más a las funciones del arte que a sus propiedades epistemológicas, lo cual no es el punto de este trabajo.

La idea de que el arte enseña a observar el mundo, quizá descubriendo aspectos que habíamos pasado por alto anteriormente, implica concebir al objeto estético como parte del lenguaje referencial. De la misma manera que la referencialidad puede denotar aspectos desconocidos del mundo, el arte puede descubrirnos aspectos del mundo antes ignorados. Lo cual está justamente encarnado en el concepto de "diferencia”. En efecto, según Derrida (1999), la diferencia no es solamente lo diferente, con relación a que un mundo posible es diferente de un mundo de hechos, sino también lo que difiere, donde la presencia -lo 
fáctico- es proyectada y en esa proyección puede ser enriquecida con otros significantes. Así, más allá del giro deconstructivista, las propiedades representacionales del arte pueden ser pensadas como el producto de significantes que abandonan la facticidad de la presencia. Mientras que las propiedades sensacionales podrían pensarse como el anclaje, el significante mismo de dicho abandono, es decir, la presencia misma.

Entre la dialéctica de la presencia y la ausencia, se encuentra el conocimiento de lo posible, más allá del mero concepto. Este conocimiento no es simple $\mathrm{u}$ original, como lo son las propiedades sensacionales, sino que es siempre polisémico. Que sea polisémico quiere decir que la obra de arte no se agota simplemente en sus significantes, sino que envuelve un racimo de significados que refieren a mundos posibles. Muchas veces esos mundos son referenciales, como ocurre con una novela, pero otras veces esos mundos son inciertos, indeterminados y no se pueden pensar referencialmente, como ocurre por ejemplo con el arte abstracto. De este modo, la idea de "experiencia polisémica del arte" debe entenderse como la capacidad de expresar más allá del signo lingüístico, incluso más allá de los objetos que conforman nuestro andar cotidiano por el mundo. Como lo que queda en la memoria es más abstracto que la mera propiedad sensacional y dicha abstracción es el producto tácito de un racimo de significados, la experiencia polisémica del arte no se articula bajo un todo de sentido. Por supuesto, también existen otras causas que no abarcan estrictamente lo estético, como por ejemplo nuestra historia personal, nuestra memoria, nuestra capacidad de asombro, etc., y hacen que se opte por un significado y no por otro; aunque todos ellos puedan ser intuitivamente semejantes. En otras palabras, que haya una experiencia polisémica del arte quiere decir que el sentido o el significado de una obra no se agotan en una única interpretación, sino que el objeto estético dice siempre más de lo que representa. Por ejemplo, un girasol pintado representa el objeto girasol, pero los girasoles pintados por Van Gogh dicen más que la mera representación del objeto: abre un mundo nuevo de percepciones.

No obstante, esto no quiere decir que no haya un significado estándar que sea aplicado, ese significado posee múltiples implicaturas, las cuales conducen a significados no estándares que son las puertas a mundos posibles lejanos al nuestro. En consecuencia, el racimo de significados 
tiene siempre una raíz que es el significado estándar que se le atribuye a la obra (que muchas veces puede estar representado por un objeto principal). El rol de la hermenéutica es justamente indagar en ese significado.

\section{Simulación e irrealidad}

Como se ha sugerido, algunos cognitivistas han sostenido que el arte brinda un tipo de conocimiento experiencial (fenoménico). Algo parecido al placer o a estar enamorado o las consecuencias trágicas de una guerra $\mathrm{o}$ a la masacre de todo un pueblo, como es el caso del Guernica de Picasso, pueden estar representados en una obra de arte. De este modo, la representación es el vínculo entre el objeto artístico y las propiedades sensacionales del sujeto. Siguiendo esta línea teórica, el arte permite la ampliación de nuestra experiencia para abarcar cosas, que de otra manera nunca se habrían experimentado o sentido. ${ }^{3}$ La experiencia polisémica que ofrece el arte, conjuntamente con sus propiedades sensacionales, está impregnada de imaginación, y se diferencia de la clase de experiencia que tendríamos si en realidad sufrimos estas cosas, pues se trata de un tipo de experiencia virtual. Por medio de la esta irrealidad somos capaces de conocer aspectos de realidades no vividas, parcelas de mundos inexistentes.

No obstante, el antagonismo entre la realidad y el contenido histórico también se manifiesta en el arte. La falta de realidad de la imagen subjetiva — subjetividad alterada- que se representa estéticamente, constituye la dialéctica entre apariencia y el contenido de verdad de la obra de arte. Dialéctica que puede ser presentada como tesis y antítesis. Puede pensarse, entonces, que la falta de realidad que integra lo que comúnmente llamamos "real" se encuentra denunciada por el arte, provocando la complexión especulativa de toda interpretación estética. De este modo, Adorno (1983) sostuvo que la clarificación racional de las obras de arte esconde un prejuicio: el de que la razón todo lo puede. En efecto, partiendo de este prejuicio, el arte es conceptualizable y, por tanto, traducible mediante explicaciones y exposiciones de carácter especulativo que conforman razones interpretativas o filosóficas. Se trata de un

3 Un defensor de este punto de vista ha sido Walsh (1969). 
análisis que alcanza el límite de la obra, convirtiéndose en su espejo: una concepción que excluye la ambición de entender el arte mediante categorías ajenas a la experiencia artística. El intento de explicar las relaciones e influencias que se derivan del arte a través de su institucionalización se debe a la presunción de que el fenómeno arte es posible al establecer determinadas normas que puedan objetivarse. Esto es importante porque el carácter intrínseco de la obra de arte dista de la actitud natural respecto al mundo de la vida, aunque, al mismo tiempo, se muestre como aspecto constitutivo la conciencia de esa actitud natural para ir más allá de ella.

Cuando lo diverso de la experiencia polisémica se integra ala identidad hermenéutica de la interpretación, entonces se produce un acercamiento entre la representación mental de la obra y su definición bajo la idea de fecundidad histórica. Ahora bien, el contenido de verdad de la obra de arte no depende de que la realidad haga su aparición, lo cual conduciría a una estética de naturaleza brechtiana, sino que el arte pondría de manifiesto un mundo alternativo - irreal si se quiere- que tiene como referencia directa un tipo de comprensión de la realidad: la realidad fáctica no es el único mundo posible y el arte puede ampliar el horizonte de realidades posibles. A razón de esto, Menke (1997) afirma que los signos estéticos admiten una diversidad de determinaciones porque se sustraen a toda identificación y se reconstruyen continuamente como material.

Por un lado, es importante dejar en claro que la experiencia polisémica del arte no está completamente desconectada con nuestra actitud natural respecto al mundo de la vida, ya que el arte mismo surge de una serie de actividades y experiencias que no son artísticas, en la facticidad misma de la cotidianidad. Por eso también, como sostiene Sparshott (1982), la historia del arte no puede considerarse aisladamente de habilidades artesanales. Por ejemplo, las habilidades de piedra o madera que se desarrollaron al servicio de las necesidades prácticas y los proyectos de ingeniería, hicieron posible la escultura. O simplemente piénsese en que la pintura es posible a partir del uso cotidiano de la inscripción en piedra de determinados símbolos. En consecuencia, el arte mismo tiene un anclaje en este mundo para evocar otros posibles.

Por otro lado, el ámbito de la experiencia polisémica de arte se extiende mucho más allá de la vida cotidiana; justamente, la polisemia implica una 
abertura del signo que excede nuestras demandas habituales de significado. Así, el arte, en su carácter enigmático, posee un rasgo imprevisible en el que cada pregunta no reclama una única respuesta y en el que cada respuesta no genera una única pregunta. Este horizonte abierto, incalculable, permite entender el aspecto incompleto de la obra de arte, tanto como su impedimento de representar lo absoluto. En su propio movimiento hacia aquello que lo excede, el arte puede considerarse como errar sin fin. Se trata, en suma, de un movimiento que ocurre desde la experiencia sensacional misma - llámese aspecto sensacional de la percepción— hacia la apropiación de aquello que parece externo a la interpretación.

El círculo hermenéutico entre la experiencia y el significado se encuentra sobre todo en la dinámica intersubjetiva: lo que se presenta intersubjetivamente como una realidad en la experiencia polisémica, tanto en su aspecto normativo como comunicativo. Así, la actitud instrumental ante la vida no es un rasgo característico del arte. Como sostenía inspiradamente Heidegger (2000): solo el arte deja-ser. Un dejar-ser que es posible comprenderlo como un dejar-ser lo que se es, para ser diferente. En el sentido de que el arte no impone trabas a aquello que puede ser (realidades posibles), pues penetra en la irrealidad tanto de nuestras emociones como de nuestra imaginación.

También la experiencia polisémica del arte se conecta profundamente con la historia, excluyendo tanto la idea de una autonomía radical del arte y su diferenciación de otras esferas como la idea de una naturaleza desinteresada de su experiencia propia. Si bien, en cuanto efecto, la experiencia estética parece ser un tipo de experiencia trascendente, en términos de Hegel: la elevación del pensamiento por encima de lo sensible. No obstante, esta trascendencia del pensamiento depende del carácter material de la obra y de su carácter multiforme. Adorno (1983) ha señalado que en toda obra de arte aparece algo que no existe, pero este no existente se muestra como si existiera, lo que podríamos llamar simulacro. El simulacro es una imagen de aquello que parece ser, pero que no es. Este No-ser no tiene un fundamento lógico, porque no está atado a un concepto determinado y menos aún la unidad entre un concepto y la realidad (el significado de verdad para Hegel). Por el contrario, el No-Ser constituye la posibilidad de la irrealidad. El valor de 
la experiencia polisémica radica en que brinda un espacio lógico para que las obras de arte simulen parcelas de mundos posibles.

Quizá se piense que las nociones de realidad e irrealidad son contradictorias y que, por este motivo, no deberían constituir un mismo objeto o experiencia. Sin embargo, ambas nociones no tienen por qué ser necesariamente opuestas, ni carecer de mediación alguna. Por el contrario, se puede afirmar dialécticamente que no se excluyen, sino que se implican mutuamente. El simulacro sería la mediación, como recreación y como engaño. Por un lado, el simulacro permite recrear una realidad que no es real para prevenirse de una realidad que es real, un experimento de la realidad: "simulemos que un edificio está en llamas para saber cómo actuar cuando el edificio esté en llamas". Por otro lado, entendido como engaño, simular es hacer creer aquello que no es, representando aquello que no está presente. De tal modo, el simulacro se caracteriza por un dominio que conformaría el contenido de apariencia propio del arte: ser lo que no es, mediante un racimo de significados. En consecuencia, mediante el simulacro el arte permite tener experiencias que representan otras experiencias que no tenemos. La simulación es una experiencia que, siendo lo que es, representa otra que no es.

Asimismo, la simulación de lo real no es una transformación ni una metamorfosis, lo cual podría derivarse de la imitación de un modelo, sino que es una especie de huida: huir de sí mismo, siendo sí mismo. Siguiendo a Levinas (1999), en la simulación se hace visible un otro que no es sí mismo, mientras que se mantiene invisible aquel que es. En consecuencia, este dominio abarca, en tanto apariencia, la ausencia que renuncia a ser imposible que fuera. Y en este sentido, la simulación se encuentra conectada con la ficción.

Se suele sugerir que la función narrativa del lenguaje se transforma en ficción cuando su empleo es socialmente reconocido como un cierto tipo de recurso en los juegos de hacer creer (p. ej., Walton, 1990), juegos que implican la simulación de un estado de cosas posibles. Así, los lectores consiguen utilizar un texto como base para un ejercicio de la imaginación, y logran simular experiencias que nunca han tenido personalmente, y pueden salir de la cotidianidad. Todo ello al identificar parcelas de mundos posibles mediante la experiencia polisémica correspondiente. Se trata de determinados significados que son aceptados para la función 
de la obra de arte, en vez de los usos para los cuales han sido diseñados. En cambio, si la narración se ha diseñado para funcionar de una determinada manera, la intencionalidad del autor juega un papel importante, de tal modo que las intenciones del autor están supuestas en la experiencia polisémica que, como se ha dicho, nunca se agota en sí misma. Por supuesto, si la ficción excluye la elección de cualquier significado, es debido a que solamente se admite un racimo de ellos como experiencia polisémica, aunque dicho racimo pueda ampliarse o reducirse en el futuro; de ahí lo inagotable. De hecho, Searle (1969/2001) sostuvo que el estado ficticio de un texto se debe a su origen en un acto de afirmación pretendida, de modo que los acontecimientos narrados se corresponden solo accidentalmente a los eventos reales en todos los detalles. Así, el autor pudo realmente haber creído que los acontecimientos narrados corresponden plenamente a una secuencia real de los hechos, aunque la experiencia polisémica los aleje de ellos.

Respecto a la dialéctica entre lo real y la irrealidad, la ficción es un producto de la experiencia estética que posee un contenido de apariencias transitorias, por lo que es siempre inconclusa, nunca total. Ya Hegel (1993) había sostenido que la apariencia es una parte esencial de la realidad: la idea de la cosa en sí, separada del pensamiento, no tiene sentido por ser vacía, una abstracción. Si no es admisible la oposición kantiana entre apariencia y cosa en sí, entre lo que aparente (fenómeno) y lo incognoscible, entonces la descripción de la realidad estaría muy cercana, al menos en un sentido metafísico, a la simulación de la realidad, pues si la realidad es lo que aparece como si fuera un evento en el mundo y la ficción consistiría en lo que aparece como si fuera un evento fuera del dominio del mundo, ¿acaso no compartirían una misma ontología la realidad y la ficción?

Ahora bien, se puede establecer una distinción entre dos tipos de imaginación. Un tipo de imaginación representacional: la que es estimulada por una copia imperfecta, como cuando decimos que un auto de juguete es una copia de un automóvil real, sin que se asemeje a un automóvil de verdad en todos o incluso muchos aspectos. En este sentido, la imaginación simula una cosa mediante semejanzas. Cuando el niño juega con el auto de juguete simula que es uno real. Esta forma de imaginación también es recreativa, no porque el evento imaginativo sea siempre o habitualmente la recreación 
literal de algún acontecimiento real concreto, sino porque no puede ser totalmente descripto sin referencia al tipo de evento que se representa. Uno puede ver en la imaginación algo que nadie más ha visto ni verá, pero el acto debe ser descripto en términos de ver esa cosa, no en términos de otra cosa que simula ser (Currie, 2010). El segundo tipo de imaginación es la creativa, la cual reúne las ideas de una manera que desafía las expectativas o convención: el tipo de imaginación implica un salto que conduce a la creación de algo valioso en el arte, la ciencia o la vida práctica.

No obstante, en el arte ambos tipos de imaginación no se encuentran radicalmente contrapuestos, pues forman parte tanto de la realidad como de la irrealidad. El arte copia la realidad y expone esa copia, aun si el artista captura algún parecido. A la vez el artista tiene una imaginación creativa, pues dicha recreación lo conduce más allá de la realidad: simula un mundo posible. También el contenido ficcional del arte puede considerarse como independiente de las intenciones del autor. El autor solamente marca una dirección mediante la disposición del material de la obra, pero tal dirección no posee un sentido propio. Y aun si lo posee, no sabemos cuál es. Este tipo desconocimiento quizá sea lo que libera al arte de cualquier intento psico-biográfico, pues la sublimación de las interpretaciones intencionales no es otra cosa que fetichismo del autor.

Así, el desarrollo de la obra de arte puede entenderse desde la conciencia misma de la experiencia estética que presenta alternativas ficticias de mundos posibles mediante su función polisémica, como desde la incógnita que propone, pues en arte nunca está dicha la última palabra: donde no hay última palabra, no hay síntesis, no hay finalidad y, en consecuencia, no hay reconciliación. Es posible incluso decir, kantianamente, que el arte es finalidad sin fin. Sin embargo, esto es solo un punto de vista interno a la dinámica de la experiencia estética. Desde un punto de vista externo, el arte también podría entenderse como una "finalidad sin fin" si fuera libre del interés del máximo beneficio. Si surgiera como categoría autónoma de las distintas influencias sociales. Aunque esto no sucede, el arte desde la experiencia estética rompe con la cadena medios-fines mediante su lenguaje no demostrativo (asignificativo) y su falta de concepto.

Nuevamente, la polisemia del arte traspasa la funcionalidad comunicativa propia de la vida diaria, pues la forma artística, como bien 
señalara Heidegger (2000), es una Stiftung (fundación, otorgamiento), en donde el lenguaje se vuelve nominación: el arte crea lo que es sagrado ante la ausencia de los dioses: mora en el hogar del ser. La finalidad del arte es la negación de toda finalidad, pero esta negación solo se alcanza desde la experiencia polisémica que da espacio al dominio de un lenguaje que no es demostrativo. Este lenguaje se separa de lo que concebimos cotidianamente como real, del contenido simbólico e institucional del arte. Si toda obra de arte es inagotable, toda experiencia estética irrepetible, se debe a que las descripciones de la realidad son inagotables y su experiencia irrepetible. Quizá también por esto el arte es a la vez continuación y quiebre de nuestras experiencias cotidianas.

Bajo este prisma, también se redefine lo que Adorno (1983) entendía por carácter de denuncia del arte. Según Adorno, el arte renuncia a la sociedad a la cual pertenece denunciando la homogeneización del pensamiento a través del discurso establecido: denuncia la imposibilidad de pensar de otra manera, por medio de un discurso represivo que encierra el pensamiento en una universalidad cerrada. El lenguaje del arte no tiene la pretensión de representar una totalidad, aunque mediante la experiencia estética también se denuncie lo que instituye su condición de posibilidad. La posibilidad de instituirse tal como se presenta. En efecto, el carácter de denuncia boicotea las condiciones de producción que le permiten al arte ser crítico con las relaciones de producción existentes. Las boicotea en tanto normatividad, proponiendo un "como si..." que excluye la normalidad (sobre todo en el arte de vanguardia), a la vez que propone una alternativa que excede cualquier uso justificado del arte. Su denuncia se contrapone a su legitimidad, por eso en una sociedad reconciliada la producción artística carecería de objeto, y esta es otra manera de entender cómo es posible la muerte del arte. En consecuencia, una de las caras del arte se maquilla con una especie de lenguaje del sufrimiento, entendiéndolo como una precondición colectivamente vinculante.

A través del simulacro, el conocimiento propio del arte es el de cierta irrealidad, pues la experiencia polisémica se revela en la negatividad del objeto representado; es decir, en el carácter transformable de lo existente. Por eso, la obra de arte también denuncia la falacia naturalista que confunde 
el Ser con el Deber Ser: No dice que las cosas no son así porque deben ser así. El conocimiento vinculado al arte permite una apuesta por la posibilidad de "lo que hay" y de "lo que hubiera si...", ya que la experiencia polisémica se encuentra, en suma, bajo la percepción de lo que carecemos.

Finalmente, la idea de un devenir abierto a sus posibilidades - a sus preguntas- que surge de la experiencia polisémica del arte puede verse como la recompensa de lo que el arte tiene de irreal. Esta modificación de lo que el sentido común considera real, como de las acciones humanas, nos moviliza, pues remueve los cimientos mismos de nuestra manera de valorar el mundo: pone entre paréntesis nuestros valores instrumentales. En este aspecto, el arte resalta el potencial del hombre para hacer frente a la integración social uniforme. La fecundidad de la experiencia polisémica se constata en la ausencia de un valor de verdad y en el quiebre con el mundo fáctico. La abertura del arte respecto a la experiencia polisémica y el pensamiento tiene una inmensa importancia tanto en el aspecto funcional del conocimiento como en los valores instrumentales de las acciones sociales. Justamente, la experiencia polisémica, al combatir las imágenes del mundo que caracterizan la identidad y la interacción de las prácticas sociales, rompe con la legalidad propia de la vida administrada - regulación de roles indiferenciadosy promueve la desorientación social.

\section{¿Experiencia polisémica sin concepto?}

Ahora bien, si el arte es una forma de conocimiento, ¿qué se conoce a través del arte? Se ha dicho que una las características del arte es la de su función polisémica: la capacidad de poseer un racimo de significados difíciles de enmarcar. Es verdad que diferentes formas artísticas revelan un contenido diferente que resulta inconmensurable, pero eso no quiere decir que tales significados no conduzcan, en todos los casos, a un alejamiento de lo real a través de la representación de mundos posibles. Mundos que causan distintas propiedades sensacionales en los sujetos. Muchas de estas propiedades son conceptualizadas y muchas no. El problema con el contenido no-conceptual de la obra de arte radica en que no puede transmitirse, y por tanto, nunca uno estará seguro de si lo tiene o no. 
Además, alguien podría argumentar que si parte de la experiencia polisémica no es conceptualizable, entonces presumiblemente se trataría de signos que carecerían de referencia y, por consiguiente, de sentido. $\mathrm{Si}$ esto fuera así, entonces solamente serían marcas y no auténticos signos, pues el signo se constituye como tal por transmitir un significado. Luego, la experiencia polisémica no podría incluir una esfera no conceptual, pues el contenido no-conceptual, excluyendo al significado, excluye al signo.

De entenderse correctamente el anterior argumento, uno puede volver a preguntarse cómo el contenido no-conceptual del arte (suponiendo que lo haya) llega a participar del conocimiento humano.

Por supuesto, el nudo del argumento anterior es muy sencillo y se resume en cinco pasos, tres premisas generales y dos conclusiones:

1. la noción de polisemia implica un poseer signos lingüísticos;

2. todo signo lingüístico se constituye por su significado;

3. el significado implica tener un concepto.

En consecuencia,

4. no puede haber polisemia sin concepto;

5. no puede haber un contenido no-conceptual en la experiencia polisémica del arte.

Uno puede aceptar la primera premisa sin ningún problema aparente, pero la segunda es más discutible. En realidad, todo el asunto gira en torno a la segunda premisa, porque se supone que si el signo se constituye a través de su capacidad de significar, entonces no abarca otra. Por tanto, que el significado implique un concepto no excluye la posibilidad de que el signo solamente encierre significado y nada más que ello. Es decir, se toma (2) como si dijera que todo signo se constituye por su significado y no envuelve nada más que ello. Si esto fuera así, entonces (3) tendría también que decir que el significado implica tener un concepto o un racimo de ellos y nada más; de la misma manera que (4) tendría que afirmar que no puede haber polisemia sin concepto y que solamente abarca un concepto o un racimo de ellos. De esta manera, seguramente se llega a (5) de manera justificada. De este modo, el razonamiento es demasiado estrecho, ya que no alcanza a probar que la experiencia polisémica del arte posee únicamente un contenido conceptual. 
Ahora bien, la cuestión no es tan sencilla para sintetizarse solo en un argumento. No cabe duda de que se puede hacer un análisis cualitativo de las condiciones etiológicas en las que la obra de arte y el concepto suelen relacionarse. No obstante, este tipo de análisis no agota la materia en cuestión, en la que las propiedades sensacionales causadas por la obra de arte son distintas de las causadas por los objetos cotidianos determinados conceptualmente. Esto equivale a afirmar que la concepción puramente dinámica de los procesos psíquicos que relacionan el desconocimiento de la irrealidad y el conocimiento propio de nuestra sensación ante ella. Así se conforma una dialéctica entre lo conocido y lo desconocido en el arte, la cual es funcional a la experiencia polisémica.

Superando la apariencia de realidad objetiva como una unidad absoluta de sentido, el arte se vuelve hacia lo diferente a la vez que denuncia el privilegio de la facticidad por sobre otros mundos posibles. Por ejemplo, los seres humanos han producido arte desde los primeros tiempos, y el arte en general se ha asociado con la religión. En ausencia del arte, la teología prosaica sería el único medio en el que la religión podría expresarse. En un principio, este tipo de arte era simbólico, expresaba su significado por una entidad sensorial que, supuestamente, posee características comunes con lo que representa, pero que no se parecen del todo. Aun en este aspecto, el arte simbólico posee un gran contenido de irrealidad; cuando contemplamos grandes monumentos dedicados a las deidades antiguas, descubrimos que intentan simular tanto su forma como su trascendencia, estimulando nuestra imaginación. Pero, además, esa simulación de trascendencia produce experiencias sensibles que, en muchos casos, no somos capaces de conceptualizar. Y esto se debe a que muchas veces las propiedades sensacionales no pueden ser reducidas causalmente a las propiedades representativas de la percepción.

Tres observaciones más. En primer lugar, la función polisémica del arte permite que la irrealidad aparezca como una forma intuitiva delibertad, en el sentido de que la apariencia constituye un horizonte de elecciones más allá de la teleología cotidiana. La libertad, en este caso, estriba en la emancipación de los sujetos de su presente mediante la introducción de significados extraños. En segundo lugar, la función polisémica del arte excluye la noción de verdad estética. Aunque uno pueda conocer 
mediante el arte, no conoce algo así como una verdad, sino las propias propiedades sensacionales cuando se abren mundos posibles simulados. Y no hay verdad porque, como se ha dicho, no hay una última palabra sino, simplemente, irrealidad. En tercer lugar, la función polisémica del arte alude al intento de que el signo estético se encuentre más allá de los significados conceptuales propios de los signos. La dinámica de la función polisémica del arte no se sitúa solamente dentro de un nivel semántico, sino que también se interrelaciona a nivel pragmático, pero desde una perspectiva trascendental. Se interrelaciona a nivel pragmático porque el arte es una práctica que está integrada institucional y socialmente a la práctica lingüística. Y esta interrelación pragmática posee una perspectiva trascendental porque cualquier objeto del mundo puede funcionar como un significante estético.

Finalmente, el contenido cognitivo del arte excede el marco de los valores de verdad entendida como adecuación con los objetos, pues al exceder el marco de la facticidad no se encuentra una referencia que concierna a un sentido absoluto o totalizante. De esta manera, solamente existen proposiciones en arte cuando se describen propiedades representativas, discriminando significados y permitiendo la homogeneización del pensamiento. Parafraseando a Wittgenstein (2002), la experiencia estética - al ser producto de significantes no-conceptuales - puede ser mostrada, pero no dicha.

\section{Conclusiones}

A lo largo de este escrito, se ha examinado la idea de que la experiencia polisémica del arte desafía al dogma de concebir una realidad como única y absoluta. Se ha sostenido también que el contenido de la obra de arte no necesariamente envuelve el concepto, pues a través de sus distintos racimos de significado, las propiedades sensacionales muchas veces no se reducen a propiedades representacionales.

Siguiendo esta línea teórica, la experiencia polisémica del arte se presenta como una alternativa del cognitivismo estético que elude el marco referencial de la verdad como adecuación del pensamiento al objeto. Este carácter polisémico permite la simulación (como si...) de 
mundos posibles que pueden no poseer objetos, o al menos no con las mismas características que los posee el mundo fáctico. En este sentido, el arte posee un carácter de denuncia: que no hay más mundos posibles que aquellos que son cercanos al mundo actual, rompiendo con la legitimidad de la vida administrada.

Epistemológicamente, que la experiencia polisémica del arte se constituya a través del simulacro de cierta irrealidad no conceptualizada quiere decir que el arte carga con un tipo de conocimiento que excede al lenguaje demostrativo. No obstante, la representación de los mundos posibles también es una parte constitutiva del conocimiento del simulacro, pues toda proyección siempre puede ser enriquecida por nuevos significantes. Significantes que implican también un conocimiento no trivial (muchas veces práctico) de parcelas de realidad que no han sido indagadas. En suma, el conocimiento estético no aparece como algo acabado en una institución o en un conjunto de interpretaciones; al contrario, continúa recreándose mediante la experiencia polisémica de quienes poseen experiencias estéticas. Teniendo como raíz un significado estándar, el racimo de significados puede alejarse tanto del mundo que uno es capaz de ofrecer una experiencia del arte que aparezca como no-conceptual.

Por último, si el arte brinda un conocimiento no trivial acerca del mundo, es en razón de entender que excede el ámbito de la facticidad, y uno puede empezar a entender este exceso a partir del propio arte. En este sentido, el arte mismo constituye un principio y un fin epistemológico.

\section{Referencias}

Adorno, Theodor. 1983. Teoría estética. Madrid: Orbis.

Adorno, Theodor. 1998. Minima Moralia. Madrid: Taurus.

Beardsmore, Richard. 1971. Art and Morality. London: Macmillan.

Currie, Gregory. 2004. Arts and Minds. Oxford: Oxford University Press. Currie, Gregory. 2010. Narratives and Narrators: A philosophy of stories. Oxford: Oxford University Press.

Diffey, Terence. 1995. What can we learn from art? Australasian Journal of Philosophy, 73(2), 204-2011. 
Evans, Gareth. 1982. The Varieties of Reference. New York: Oxford University Press.

Goodman, Nelson. 1976. Lenguages of Art. Indianapolis: Hackett.

Hegel, Georg. Wilhelm. 1993. Ciencia de la lógica. Buenos Aires: Hachette.

Heidegger, Martin. 2000. Hitos. Madrid: Alianza.

Levinas, Emmanuel. 1999. Totalidad e infinito. Salamanca: Síguenme.

Marcuse, Albert. 1982. La dimensión estética. Barcelona : Edicions 62.

McDowell, John. 2003. Mente y Mundo. Salamanca: Sígueme.

Menke, Cristoph. 1997. La soberanía del arte: la experiencia estética según Adorno y Derrida. Madrid: Visor.

Nussbaum, Martha. 1990. Love's Knowledge: Essays on Philosophy and Literature. Oxford: Oxford University Press.

Peacocke, Cristopher. 1992. A Study of Concepts. Massachusetts: MIT Press.

Peacocke, Cristopher. 2001. Does Perception Have a Nonconceptual Content? The Journal of Philosophy, 98, 239-264.

Putnam, Hilary. 1978. Meaning and The Moral Sciences. London: Routledge. Robinson, Jenefer. 2005. Deeper than reason: Emotion and its role in literature, music, and art. Oxford: Clarendon Press.

Searle, John. 2001. Actos de Habla. Madrid: Cátedra.

Sparshott, Francis. Edward. 1982. The theory of the arts. Princeton: Princeton University Press.

Stolnitz, Jerome. 1992. On the Cognitive Triviality of Art. British Journal of Aesthetics, 32, 191-200.

Walsh, Dorothy. 1969. Literature and Knowledge. Middletown: Wesleyan University Press.

Walton, Kendall. 1993. Metaphor and Prop Oriented Make-Believe. European Journal of Philosophy, 1(1), 39-57.

Wittgenstein, Ludwig. 2002. Tractatus Logicus Philosophicus. Madrid: Tecnos.

Wittgentein, Ludwig. 1992. Lecciones y conversaciones sobre estética, psicología y creencia religiosa. Barcelona: Paidós. 